\title{
Definindo o comentário metadiscursivo em uma perspectiva interacionista da Análise do Discurso
}

\author{
Gustavo Ximenes Cunha* \\ Paloma Bernardino Braga**
}

\begin{abstract}
Resumo
Este trabalho apresenta os resultados de pesquisa que buscou definir a noção de comentário metadiscursivo. Adotando contribuições teórico-metodológicas de uma abordagem interacionista da Análise do Discurso, o Modelo de Análise Modular do Discurso, a pesquisa teve como base empírica dois debates eleitorais. O primeiro aconteceu em 2012 e foi protagonizado por Fernando Haddad (PT) e José Serra (PSDB), e o segundo ocorreu em 2014 e foi protagonizado por Dilma Rousseff (PT) e Aécio Neves (PSDB). Ao final do percurso de análise, foi possível definir o comentário metadiscursivo como uma relação de discurso por meio da qual o locutor emprega um segmento de discurso representado para comentar, avaliando, uma informação da memória discursiva cuja origem é o comportamento linguageiro do próprio locutor (comentário metadiscursivo autofônico), do interlocutor (comentário metadiscursivo diafônico) ou de terceiro (comentário metadiscursivo polifônico).
\end{abstract}

Palavras-chave: Comentário metadiscursivo. Debate eleitoral. Polifonia.

\section{Defining The Metadiscursive Commentary in an Interactionist Perspective of Discourse Analysis}

\begin{abstract}
This paper presents the results of a research whose purpose was to define the notion of metadiscursive commentary. Adopting theoretical-methodological contributions from an interactionist approach to Discourse Analysis, the Modular Approach to Discourse Analysis, the research studied two electoral debates: Fernando Haddad (PT) and José Serra (PSDB) (2012); Dilma Rousseff (PT) and Aécio Neves (PSDB) (2014). With the analysis, it was possible to define the metadiscursive comment as: a discourse relation through which the speaker uses a segment of discourse represented to comment, by evaluating, an information of the discursive memory whose origin is the speaker's linguistic behavior (autophonic metadiscursive commentary), the linguistic behavior of the interlocutor (diaphonic metadiscursive commentary) or the third-party linguistic behavior (polyphonic metadiscursive commentary).
\end{abstract}

Keywords: Metadiscursive commentary. Electoral debate. Polyphony.

Recebido: 01/12/2017

Aceito: 14/04/2018

\footnotetext{
* Universidade Federal de Minas Gerais (UFMG). Doutor em Linguística e professor da Faculdade de Letras e do Programa de Pós-graduação em Estudos Linguísticos (POSLIN) da UFMG. Coordena o Grupo de Estudos sobre a Articulação do Discurso (GEAD/UFMG).

** Universidade Federal de Minas Gerais (UFMG). Bolsista de iniciação científica (PIBIC-CNPq) no projeto "O papel do comentário metadiscursivo na construção de debates eleitorais". Integrante do GEAD (UFMG).
} 


\section{Introdução}

Neste trabalho, apresentamos os resultados de pesquisa cujo propósito central foi o de definir o comentário metadiscursivo, definição que evidenciasse a natureza complexa do conceito ${ }^{3}$. Na linguística do texto e do discurso, este termo costuma ser empregado em trabalhos que se filiam à corrente interacionista dos estudos da linguagem (KERBRAT-ORECCHIONI, 1992), tendo em vista a percepção de que esse tipo de comentário exerce papel importante na maneira como os interlocutores regulam conjuntamente sua participação na interação. Mas, apesar dessa percepção comum da natureza interacional desse tipo de comentário, o termo, quando empregado, remete a fenômenos distintos, embora aproximados.

Sem pretensão de exaustividade, verificamos que se emprega o termo para se referir tanto à operação por meio da qual um locutor expressa uma opinião ou ponto de vista sobre segmento (palavra, sintagma, sentença ou porção mais extensa) do discurso precedente (KOSTCHI, 1986), quanto à relação de discurso em que o locutor suspende o tópico em curso para fazer observações sobre a situação de comunicação (ROULET, 2004). O mesmo termo pode ser empregado ainda para nomear intercalações que, com funções diversas, interrompem o desenvolvimento do tópico central (SERAFIM, 2010). Nesse outro sentido, o termo não nomeia uma relação de discurso, mas uma porção do texto que suspende momentaneamente o tópico para focalizar informações periféricas e mais ou menos relacionadas ao tópico central (JUBRAN, 2005). Na tentativa de superar essa flutuação conceitual $^{4}$ e circunscrever melhor a noção, propusemos, em trabalho anterior, a seguinte definição para o comentário metadiscursivo:

relação de discurso em que o locutor liga a intervenção que produz a uma informação previamente estocada na memória discursiva [conhecimentos partilhados], com o fim de avaliar positiva ou negativamente essa informação. Além disso, para poder ser caracterizado como metadiscursivo, o comentário precisa avaliar não a carga semântica de determinada porção textual, mas sim elementos relativos à situação de comunicação, tais como o desempenho dos candidatos na formulação de suas intervenções, as normas que subjazem ao debate ou mesmo à sociedade, as atitudes tomadas pelos interlocutores, a pertinência ou não da escolha de determinadas palavras etc. (CUNHA; BRAGA, 2016, p. 116.)

Enquanto conceituação preliminar, essa definição nos permitiu atentar para a complexidade da noção, por explicitar que sua compreensão requer informações não apenas textuais ou ligadas à estrutura do texto, mas ainda informações situacionais, relacionadas ao contexto de produção do discurso, e enunciativas, ligadas às instâncias às quais se atribui a responsabilidade pelas informações expressas. Porém, essa definição carece de rigor, tendo em vista a heterogeneidade dos elementos que podem constituir o alvo do comentário metadiscursivo. Porque essa heterogeneidade mostrou-se pouco operatória no trabalho empírico de identificação de comentários metadiscursivos presentes em discursos específicos, a definição precisou ser revista. $\mathrm{O}$ objetivo deste trabalho consiste, portanto, em apresentar o resultado dessa revisão.

Para alcançar esse objetivo, a pesquisa teve como base empírica dois debates eleitorais. O primeiro foi o último debate da campanha pela prefeitura de São Paulo ocorrida em 2012, do qual participaram Fernando Haddad (PT) e José Serra (PSDB). O segundo debate foi o último da campanha presidencial ocorrida em 2014, do qual participaram Dilma Rousseff (PT) e Aécio Neves (PSDB). Ambos os debates foram promovidos pelo mesmo veículo de comunicação, a Rede Globo 5 .

3 A pesquisa, que se intitula "O papel do comentário metadiscursivo na construção de debates eleitorais", foi desenvolvida
no período de 07/2016 a 07/2017, na Faculdade de Letras da UFMG, e contou com o apoio do CNPq.
4 Flutuação conceitual semelhante é constatada por Hyland (2017), em ampla revisão de estudos sobre a noção de
metadiscurso.
5 Os debates analisados foram transcritos e divulgados, respectivamente, pelo jornal Folha de S. Paulo ( $<$ http://www1. 
Do ponto de vista teórico-metodológico, a pesquisa adotou contribuições do Modelo de Análise Modular do Discurso. Em linhas gerais, o modelo modular é uma abordagem interacionista da Análise do Discurso, cuja finalidade é descrever e explicar a complexidade da organização do discurso (ROULET; FILLIETTAZ; GROBET, 2001). Subjazem ao modelo algumas exigências próprias da vertente interacionista dos estudos da linguagem (KERBRAT-ORECCHIONI, 1992), tais como admitir que a função fundamental da linguagem é de ordem comunicativa; evitar reduzir a comunicação à mera transmissão de informações entre sujeitos isolados de todo contexto histórico e social; reconhecer a natureza dialógica de todo enunciado, mesmo daqueles que superficialmente sejam monologais ou produzidos por um único locutor (ROULET; FILLIETTAZ; GROBET, 2001). Por adotar tal perspectiva epistemológica, o modelo define o discurso como interação verbal situada resultante da combinação de informações de três dimensões: linguística, textual e situacional.

Tendo em vista a complexidade e heterogeneidade das informações que participam da composição do discurso, o modelo propõe que o estudo dessa composição se realize por meio de uma metodologia modular. Assim, esse estudo se faz com o auxílio de módulos, que correspondem a sistemas de informações elementares, cujo papel é o de fornecer a descrição de um domínio específico da organização discursiva. Os módulos propostos pelo modelo são: lexical, sintático, hierárquico, referencial e interacional.

Os módulos não correspondem a domínios estanques de informações. Ao contrário, na produção e na compreensão do discurso, as informações modulares se combinam. Por exemplo, a compreensão do papel que exerce determinado conector, como o mas ou o portanto, implica a consideração não apenas de informações lexicais (sobre o item linguístico), mas ainda de informações hierárquicas (sobre a estrutura do texto) e referenciais (sobre as representações conceituais articuladas pelo conector). Assim, o modelo propõe que as informações modulares se combinam em formas de organização do discurso, que podem ser elementares ou complexas. As elementares (fono-prosódica, semântica, relacional, informacional, enunciativa, sequencial e operacional) resultam da combinação de informações extraídas do estudo dos módulos, ao passo que as complexas (periódica, tópica, polifônica, composicional e estratégica) são resultantes da combinação de informações extraídas do estudo dos módulos e das formas de organização elementares e/ou complexas (ROULET, 1999, ROULET; FILLIETTAZ; GROBET, 2001, CUNHA, 2014).

Como já ressaltado por Roulet (1999), uma das vantagens de se adotar uma abordagem modular é possibilitar ao pesquisador definir noções complexas, como o comentário metadiscursivo, a partir da combinação de informações mais elementares, por meio de um procedimento de análise que combina essas informações de maneira controlada e progressiva. Por isso, para que chegássemos a uma definição considerada satisfatória do comentário metadiscursivo, seguimos um percurso de análise composto pelas seguintes etapas:

1) Módulo referencial: descrição do gênero debate eleitoral.

2) Forma de organização relacional: identificação dos comentários presentes no corpus formado pelos debates eleitorais.

3) Forma de organização polifônica: essa etapa se desdobrou em duas subetapas: $1^{\text {a }}$ ) identificação, no conjunto dos comentários identificados na etapa precedente, daqueles que retomam (representam, citam, pressupõem, fazem alusão a, polemizam com) o discurso de diferentes instâncias enunciativas e que, por isso, são metadiscursivos; $2^{\mathrm{a}}$ ) estudo das funções que o comentário metadiscursivo exerce nos debates estudados. 
A apresentação de cada uma das etapas e subetapas será realizada nos itens a seguir. Ao final do estudo dessas etapas e subetapas, apresentaremos, nas Considerações finais, nossa proposta de definição do comentário metadiscursivo.

\section{Módulo referencial: características típicas do debate eleitoral}

O módulo referencial estuda as relações que o discurso estabelece com o mundo em que é produzido (a situação de ação), bem como as relações que o discurso mantém com os mundos que representa (FILLIETTAZ, 2000, CUNHA, 2014). Um dos instrumentos de análise desse módulo é a representação conceitual. Conforme Filliettaz e Roulet (2002), os interlocutores dispõem de conhecimentos esquemáticos acerca dos objetos, seres e noções, conhecimentos que, atuando como expectativas de ordem sócio-cultural, são mobilizados na interação. Em linhas gerais, a finalidade da representação conceitual é explicitar esses conhecimentos esquemáticos, que são entendidos como propriedades que podem ser atribuídas a conceitos e que se caracterizam por seu forte grau de tipicidade (ROULET; FILLIETTAZ; GROBET, 2001) ${ }^{6}$. Este trabalho se vale da representação conceitual para reunir propriedades típicas ou recorrentes do mundo em que os debates analisados se inserem, inventariando as expectativas de ordem genérica do debate.

Independentemente da vertente teórica seguida pelos vários trabalhos que, nas últimas décadas, têm se dedicado a compreender o gênero debate eleitoral, todos reconhecem a natureza conflituosa do gênero. Em outros termos, é consensual a ideia de que o debate se define por colocar em cena candidatos a cargos políticos que exibem visões divergentes e antagônicas do mundo social, contribuindo para a construção de uma polarização bastante marcada na maneira de compreender tópicos de interesse da população (AQUINO, 2008, AMOSSY, 2017, BURGER, 2004, SILVA, 2013, MARTEL, 2008, SANDRÉ, 2009, SULLET-NYLANDER; ROITMAN, 2009). Assim, o debate pode ser entendido como uma prática social cujos atores principais (os adversários políticos) assumem posições diametralmente opostas no que se refere às questões de interesse público, tais como saúde, educação, transporte, moradia, gestão dos recursos públicos etc. É uma característica da posição assumida por um candidato em debate a assunção de opiniões que sejam divergentes em relação àquelas assumidas pelo adversário. Portanto, pode-se apontar o dissenso acerca dos tópicos abordados como traço mais característico do gênero debate (AMOSSY, 2017).

Além dos adversários políticos, outros atores participam do debate. De central importância para compreender o comportamento linguageiro e não linguageiro assumido pelos adversários é a plateia, que, dependendo do suporte, é constituída por ouvintes (rádio), telespectadores (televisão) ou internautas (internet). Mais recentemente, especialmente as emissoras de televisão têm colocado, no estúdio em que se realiza o debate, uma plateia formada supostamente por eleitores indecisos, cuja função é representar os eleitores de modo geral. Porque cada adversário precisa dirigir-se a essa plateia (ausente ou presente), fazendo com que ela creia que suas capacidades são superiores às do oponente, a plateia desempenha um papel essencial, na medida em que convencê-la constitui a razão de ser do debate (SANDRÉ, 2009, SULLET-NYLANDER; ROITMAN, 2009). Essa necessidade de convencimento dos espectadores explica, inclusive, por que o dissenso e não o consenso constitui o traço mais característico do gênero. Uma vez que os integrantes da plateia precisam decidir qual dos candidatos é o mais adequado para o cargo em disputa, cada candidato busca apresentar-se como a

6 O módulo referencial estuda não só os conceitos mobilizados pelos interlocutores numa dada interação, mas também as identidades assumidas e negociadas por eles, as ações que tipicamente realizam numa interação, bem como as ações que efetivamente realizam. Para descrever esses aspectos do modo de participação dos interlocutores numa interação, o módulo referencial propõe ainda outros instrumentos de análise, que são a representação praxeológica, a estrutura praxeológica, a estrutura conceitual e o quadro acional (FILLIETTAZ, 2000, ROULET; FILLIETTAZ; GROBET, 2001). 
única solução para os males vivenciados pela população que a plateia simboliza e, ao mesmo tempo, apresentar o adversário como a causa dos males ou como aquele cujo governo poderá perpetuar ou agravar esses males (CUNHA, 2014a).

Exibindo participação mais periférica, mas essencial para o funcionamento do debate, o mediador é um jornalista cujo propósito é garantir que as regras estruturais da interação de que participa sejam respeitadas ao longo do debate. Assim, espera-se que aquele que assume a posição de mediador proíba que um candidato fale no intervalo de tempo reservado à fala do outro, contenha manifestações excessivas ou inoportunas da plateia (palmas, gritos, vaias, ofensas etc.), quando há uma plateia no estúdio, impeça que cada candidato fale por mais tempo do que o permitido, repreenda o candidato que utiliza ofensas e xingamentos para atacar o adversário etc.

O antagonismo dos adversários bem como a existência de uma plateia em função da qual esse antagonismo se acirra explicam a linguagem usada no debate pelos candidatos. Sendo o dissenso acerca dos tópicos abordados o traço mais característico do debate, a expectativa é a de que a linguagem se caracterize por ser essencialmente polêmica (AMOSSY, 2017). Sem pretender apresentar um inventário exaustivo de recursos linguísticos que contribuem para tornar a linguagem dos candidatos polêmica, apresentamos uma relação de recursos que, com base em estudiosos do gênero, são típicos da linguagem agressiva empregada por políticos em debates: ironias, negações da fala do outro, perguntas retóricas cuja finalidade é colocar o adversário em uma posição embaraçosa, atos de fala agressivos para a face do oponente, tais como acusações, críticas e perguntas invasivas, estabelecimento de relações de contra-argumentação por meio das quais o locutor opõe suas qualidades e méritos aos defeitos e deméritos do oponente, marcação dessas relações por conectores contraargumentativos, modalizadores, representação de discursos de terceiros que supostamente atestam a participação do adversário em operações fraudulentas etc. (BURGER, 2004, SILVA, 2013, SANDRÉ, 2009, SULLET-NYLANDER; ROITMAN, 2009).

Embora as propriedades elencadas neste item (finalidade geral: apresentação de pontos de vista antagônicos sobre a realidade; participantes da interação: adversários, plateia e mediador - e uso agressivo da linguagem) não esgotem as que podem ser tipicamente associadas ao gênero debate, consideramos que elas permitem uma compreensão satisfatória do mundo em que um debate eleitoral se insere ou da situação característica de um debate, podendo constituir a representação conceitual desse gênero. Isso porque essas propriedades correspondem a expectativas esquemáticas essenciais que todo aquele que participa de um debate ou assiste a um debate precisa mobilizar para compreender o que se passa nesse tipo de interação. Adiante, as informações deste item sobre a representação conceitual do debate serão combinadas, no interior da forma de organização polifônica, com as informações extraídas do estudo das formas de organização relacional e enunciativa.

\section{Forma de organização relacional}

A forma de organização relacional resulta da combinação de informações extraídas dos módulos hierárquico, referencial, lexical e sintático e tem como objetivo a identificação das relações de discurso ilocucionárias e interativas que se estabelecem entre os constituintes do texto e informações previamente estocadas na memória discursiva (conjunto de saberes partilhados pelos interlocutores). Central para essa forma de organização é a noção de estrutura hierárquica, cujo estudo se realiza no módulo hierárquico. Essa estrutura tem a finalidade de representar o processo de negociação que ocorre entre os interlocutores e por meio do qual o estudioso pode verificar se os interlocutores 
produziram ou não intervenções suficientemente completas e adequadas para a interação, atendendo ao princípio de completude monológica, e se alcançaram ou não o "duplo acordo", chegando ao fim da interação e atendendo ao princípio de completude dialógica (ROULET, FILLIETTAZ, GROBET, 2001, CUNHA, 2017).

$\mathrm{Na}$ forma de organização relacional, a combinação da estrutura hierárquica com informações de ordem referencial, lexical e sintática permite identificar as manobras linguageiras que os interlocutores realizam para participarem da interação. Essas manobras são as relações de discurso que ligam um constituinte do texto (ato, intervenção ou troca) a informações estocadas na memória discursiva. No modelo, são propostos dois tipos de relações de discurso: ilocucionárias e interativas. As ilocucionárias são as que articulam os constituintes de uma troca (iniciativas - interrogação, pedido e informação - e reativas - resposta e ratificação). Já as relações interativas são as que articulam os constituintes das intervenções (argumento, contra-argumento, reformulação, topicalização, sucessão/ tempo, preparação, comentário e clarificação). Ambos os tipos de relações podem ser sinalizados por conectores (módulos lexical) e/ou por estruturas sintáticas (módulo sintático) (ROULET, FILLIETTAZ, GROBET, 2001).

Neste trabalho, o estudo da forma de organização relacional permitiu identificar todas as ocorrências das relações de comentário presentes nos debates componentes do corpus. Foi encontrado um total de 265 relações de comentário nos dois debates estudados: 114 (43\%) no debate entre Fernando Haddad e José Serra ${ }^{7}$ e 151 (57\%) no debate entre Dilma Rousseff e Aécio Neves. A relação de comentário articula um constituinte subordinado (o comentário) a uma informação previamente estocada na memória discursiva (o alvo do comentário ou aquilo que o locutor comenta). Em muitas ocorrências das relações de comentário, as informações da memória discursiva em que um constituinte se liga costumam ter origem no constituinte imediatamente anterior. É o que ocorre neste trecho extraído da fala de Fernando Haddad.

Fernando Haddad: (5) É obrigação do prefeito buscar recursos federais, inclusive na área social, para o transporte (6) que vai mal $(. . .)^{8}$.

O ato (6) (que vai mal) traz um comentário que se liga a uma informação da memória discursiva (transporte) ativada no ato imediatamente anterior. Essa interpretação pode ser representada por meio da estrutura hierárquica a seguir $($ intervenção $=\mathrm{I} ;$ ato $=\mathrm{A}$; principal $=\mathrm{p}$; subordinado $=\mathrm{s}$; comentário $=$ com).

I

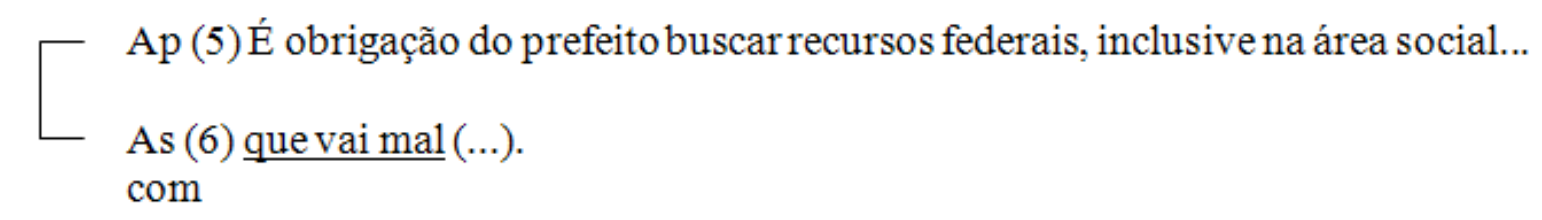

Porém, nem todas as ocorrências de comentários identificadas articulam um constituinte textual a uma informação da memória discursiva com origem em um constituinte imediatamente anterior. É o que ocorre neste fragmento, cujo trecho sublinhado é um comentário:

Dilma Rousseff: (1) Candidato, eu sempre gosto de perguntar a respeito do Pronatec. (...) (5) Vocês

7 A identificação das relações de comentário no debate de que participaram Fernando Haddad e José Serra se beneficiou de pesquisa anteriormente realizada sobre as relações de discurso nesse mesmo debate (CUNHA, 2015).

$8 \mathrm{Em}$ todos os excertos apresentados neste trabalho, a numeração indica a segmentação dos debates em atos. O ato é a unidade mínima de análise do modelo modular (ROULET; FILLIETTAZ; GROBET, 2001). 
fizeram uma lei proibindo que o governo federal fizesse e mantivesse escolas técnicas. (6) Por isso fizeram, ao longo de oito anos, só 11 escolas técnicas. (7) O senhor era líder do governo FHC. (8) O senhor vai continuar com essa política?

Aécio Neves: (1) Eu não devia lhe corrigir em público, (2) mas eu era líder do PSDB, (3) mas vamos passar isso, (4) deixar isso um pouco mais barato. (5) É, mais ou menos candidata. (6) Para quem não conhece o Congresso Nacional, (7) talvez sim, (8) mas é muito diferente, (9) é muito diferente. (...) (11) Candidata, o Pronatec é uma inspiração (12) e é bom reconhecer isso.

Nos atos (1-9) de sua resposta, o candidato comenta a informação ativada no ato (7) da fala da adversária: O senhor era líder do governo FHC. Assim, o comentário se liga a uma informação da memória discursiva que não tem origem em um constituinte imediatamente anterior. É apenas a partir do ato (11) que o candidato passa a responder à pergunta da adversária. Com base em Roulet (2003), quando um constituinte se liga a uma informação cuja origem não é o constituinte imediatamente anterior, deve-se introduzir, na estrutura hierárquica, a informação da memória discursiva em que o constituinte se liga. A estrutura hierárquica do fragmento anterior pode ser construída desta forma $($ troca $=\mathrm{T}$; intervenção $=\mathrm{I}$; memória discursiva $=\mathrm{M}$; principal $=\mathrm{p}$; $\operatorname{subordinado}=\mathrm{s}$; iniciativa $=$ in; reativa $=$ re; preparação $=$ pre; comentário $=$ com $)$.

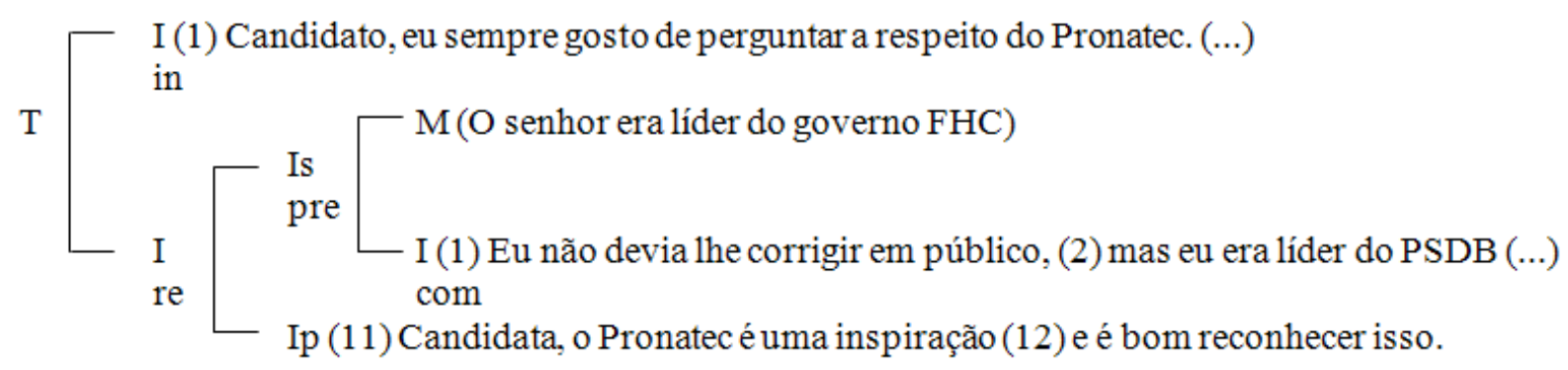

Há ainda ocorrências em que a informação da memória discursiva que é o alvo do comentário não foi ativada em nenhum ato, mas constitui uma inferência do locutor feita a partir do que o adversário disse, como neste trecho:

Fernando Haddad: (...) (5) Eu queria saber se você como prefeito, governador, se sente responsável de alguma maneira por isso [aumento da criminalidade] (6) ou se os seus sucessores têm alguma responsabilidade (7) e o que pretende fazer pela segurança?

José Serra: (1) O que eu devo dizer pela segurança é o seguinte, (2) como prefeito eu vou da batalha, (3) vou ser um prefeito ativista (4) para ajudar o Governo do Estado na tarefa da segurança. (...)

Fernando Haddad: (1) Bom, o candidato não respondeu a que atribui a escalada da violência no último ano. (2) Dobrou o número de assassinatos na cidade de São Paulo.

No trecho sublinhado, o candidato não comenta as propostas apresentadas pelo adversário, defendendo, por exemplo, se seriam adequadas ou não, mas faz um comentário sobre a natureza do ato de fala (resposta) do adversário, mostrando que este não teria sido feliz em sua formulação. Em outros termos, Haddad comenta, criticando, a incapacidade do oponente de produzir o ato de fala desejado (uma resposta à pergunta). Essa interpretação pode ser representada desta maneira: 


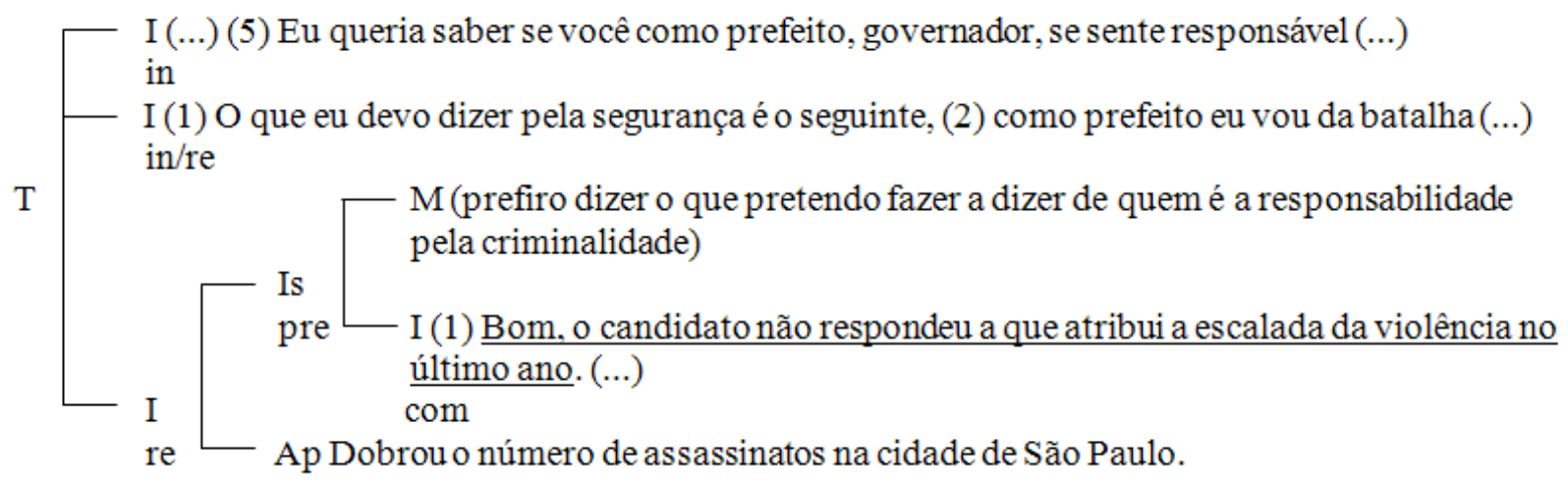

Essas observações ilustram a diversidade e a complexidade de tipos de comentários encontrados no corpus. Como veremos adiante, muitos desses comentários que se ligam a informações cuja origem não é o constituinte imediatamente anterior são metadiscursivos, exatamente por serem comentários do locutor sobre partes localizadas da fala do oponente ou sobre o comportamento linguageiro ou não linguageiro do adversário e de terceiros ou sobre seu próprio comportamento. Mas vale esclarecer que o estudo da forma de organização relacional não permite identificar, no conjunto dos comentários encontrados, aqueles que são metadiscursivos. Essa identificação necessita da combinação, no interior da forma de organização polifônica, de informações da forma de organização relacional com informações da forma de organização enunciativa e do módulo referencial.

\section{Forma de organização polifônica}

A finalidade dessa forma de organização é explicar as formas assumidas pelos segmentos de discursos representados em produções discursivas específicas, bem como definir as funções que esses segmentos exercem nessas produções. Essa é uma forma de organização considerada complexa, na medida em que, para explicar as formas e definir as funções dos discursos representados, seu estudo depende da acoplagem de informações extraídas da forma de organização enunciativa, que descreve os tipos e as formas dos segmentos de discursos representados, com outras formas de organização e módulos do discurso (ROULET, FILLIETTAZ, GROBET, 2001).

Como exposto na introdução, neste trabalho o estudo da forma de organização polifônica se fez em duas subetapas: na primeira, extraímos do conjunto dos comentários identificados com o estudo da forma de organização relacional aqueles em que o locutor representa (cita, pressupõe, faz alusão a, polemiza com) o discurso de diferentes instâncias enunciativas e que, por isso, são metadiscursivos; na segunda, estudamos as funções que o comentário metadiscursivo exerce nos debates estudados, combinando os resultados da primeira subetapa, que identificou os comentários metadiscursivos, com os resultados do estudo do módulo referencial, apresentado no item 2 deste trabalho.

\subsection{Combinação das formas de organização enunciativa e relacional}

A forma de organização enunciativa resulta da combinação das informações dos módulos lexical, sintático, interacional e referencial e tem como objetivo distinguir os discursos produzidos dos discursos representados e, a partir dessa distinção, descrever os tipos de discurso representado e as características formais dos discursos representados (ROULET; FILLIETTAZ; GROBET, 2001). 
A distinção de discursos produzidos e representados se faz com o estudo do módulo interacional. Esse módulo "descreve as propriedades materiais da interação, levando em conta o canal (oral, escrito, visual), o modo (distância ou copresença espacial e/ou temporal) e o tipo de vínculo da interação (existência ou não de reciprocidade)." (CUNHA, 2014, p. 31). O resultado do estudo desse módulo é um quadro que permite visualizar os diferentes níveis de embotamento interacional que caracterizam determinado discurso, bem como as propriedades materiais de cada nível. A figura 1 corresponde ao quadro interacional dos debates estudados nesta pesquisa ${ }^{9}$ :

Figura 1: quadro interacional

\begin{tabular}{|c|c|c|c|c|}
\hline $\begin{array}{l}\text { emissora } \\
<\text { Rede } \\
\text { Globo> }\end{array}$ & $\begin{array}{l}\text { locutor } \\
\text { <adversár> } \\
\text { oral evisual } \\
\text { co-presença } \\
\text { reciprocidad }\end{array}$ & $\begin{array}{l}\begin{array}{l}\text { interlocutor } \\
\text { <person>> }\end{array} \\
\text { oral e/ou escrito } \\
\text { co-presença ou distância espaço- } \\
\text { temporal } \\
\text { (não) reciprocidade } \\
\text { spaço-temporal }\end{array}$ & $\begin{array}{l}\text { locutor } \\
<\text { adversár > } \\
<\text { espectad }>\end{array}$ & espectadores \\
\hline
\end{tabular}

Fonte: Elaboração dos autores.

Segundo Marinho (2004, p. 94), os discursos produzidos são "os enunciados pelos locutores/ escritores que ocupam o nível mais externo no quadro interacional”, enquanto os representados "são enunciados pelos locutores/escritores que ocupam os níveis mais internos da interação". Com base no quadro proposto para os debates componentes do corpus, é possível verificar que a distinção entre discurso produzido e discurso representado é relativa, já que os discursos são produzidos ou representados, dependendo do nível interacional considerado pelo pesquisador. No quadro, o discurso dos adversários políticos e de integrantes da plateia (espectadores) convidados a fazer perguntas é representado em relação ao discurso produzido pela emissora de televisão que produz e transmite o debate. Mas, ao mesmo tempo, esse mesmo discurso dos adversários e espectadores é produzido em relação ao discurso das personagens que eles representam em suas intervenções.

$\mathrm{Na}$ forma de organização enunciativa, o módulo interacional auxilia ainda na definição dos tipos de discurso representado: diafônico, polifônico e autofônico. O segmento de discurso é autofônico se nele o locutor representa seu próprio discurso; é diafônico, se nele o locutor representa o discurso de seu interlocutor direto, aquele com quem o locutor compartilha o mesmo nível interacional; e é polifônico, se nele o locutor representa o discurso de instâncias localizadas em outros níveis interacionais (o discurso de personagens, por exemplo). (ROULET; FILLIETTAZ; GROBET, 2001).

Quanto à forma, os discursos representados podem ser designados, formulados ou implicitados. O discurso designado ocorre na forma de um verbo (suplicar, reclamar) ou de uma nominalização (súplica, reclamação) que remete a um dito. O discurso formulado abarca as formas tradicionais do discurso direto, indireto e indireto livre. Já o discurso implicitado corresponde a um conector, geralmente em início de réplica, por meio do qual o locutor liga o constituinte textual que introduz a uma informação da memória discursiva com origem em discurso produzido pelo interlocutor (ROULET; FILLIETTAZ; GROBET, 2001, CUNHA; MARINHO, 2017).

9 Uma versão próxima desse quadro foi proposta para o debate eleitoral protagonizado por Fernando Haddad e José Serra em Cunha e Marinho (2017). 
Neste trabalho, o estudo da forma de organização enunciativa focalizou as intervenções dos debates eleitorais que, na etapa anterior (forma de organização relacional), identificamos como sendo comentários. Esse estudo se fez em dois momentos. No primeiro, a finalidade foi identificar os comentários que trazem segmentos de discurso representado. Na etapa anterior, identificamos um total de 265 relações de comentário, sendo 114 no debate entre Fernando Haddad e José Serra e 151 no debate entre Dilma Rousseff e Aécio Neves. Com o estudo da forma de organização enunciativa, verificamos que, em 121 (45\%) das 265 relações de comentário, a intervenção que expressa o comentário traz um segmento de discurso representado, sendo 52 (42\%) no debate entre Fernando Haddad e José Serra e 69 (58\%) no debate entre Dilma Rousseff e Aécio Neves.

Em todas essas 121 ocorrências, o locutor comenta, avaliando positiva ou negativamente, seu próprio comportamento linguageiro ou o comportamento linguageiro do interlocutor ou de terceiros. É o que ocorre neste trecho:

Dilma Rousseff: (...) (5) O senhor concorda com o que fala o seu candidato a Ministro da Fazenda, (6) que diz que o salário mínimo está alto demais?

Aécio Neves: (1) Candidata, não é justo colocar palavras na boca de alguém que não está aqui para respondê-la. (...)

No trecho, o candidato articula o comentário com que introduz sua resposta (ato 1) à pergunta feita pela adversária. O comentário constitui um segmento de discurso representado, já que nele o candidato representa, retomando, a pergunta da adversária, para informar (aos espectadores/eleitores) que essa pergunta constitui uma injustiça contra um integrante da equipe do candidato.

Tendo em vista que essas 121 ocorrências de comentários são segmentos de discursos representados, consideramos que essas ocorrências, diferentemente das outras 144 ocorrências de comentários identificadas no estudo da forma de organização relacional, são metadiscursivas. Assim, da perspectiva adotada neste trabalho, um comentário para ser metadiscursivo precisa, no plano enunciativo, ser um segmento de discurso representado. Afinal, é o fato de retomar para avaliar o comportamento linguageiro de alguma instância enunciativa (o próprio locutor, o interlocutor ou um terceiro) que dá a esse comentário sua natureza metadiscursiva. A tabela 1 evidencia o total de comentários metadiscursivos por debate, bem como o total de comentários metadiscursivos produzidos por candidato.

Tabela 1: total de comentários metadiscursivos por debate

\begin{tabular}{|l|c|c|}
\hline \multicolumn{1}{|c|}{ Candidatos } & N & $\mathbf{~ \% ~}$ \\
\hline José Serra & 19 & 36,5 \\
\hline Fernando Haddad & 33 & 63,5 \\
\hline Total & 52 & 100 \\
\hline Dilma Rousseff & 31 & 44,9 \\
\hline Aécio Neves & 38 & 55,1 \\
\hline Total & 69 & 100 \\
\hline
\end{tabular}

Fonte: Elaboração dos autores.

Podemos notar que os candidatos que, em cada debate, são os da oposição, Fernando Haddad e Aécio Neves, realizaram mais comentários metadiscursivos do que os candidatos da situação, José Serra e Dilma Rousseff. As razões para esse resultado serão discutidas no próximo item, com base em informações de ordem referencial. 
No segundo momento do estudo da combinação das formas de organização relacional e enunciativa, focalizamos apenas os 121 comentários metadiscursivos, a fim de verificar o tipo de discurso representado que cada um deles traz, se autofônico (o locutor representa seu próprio discurso ou comenta sua própria fala), se diafônico (o locutor representa o discurso do interlocutor ou comenta a fala do interlocutor) ou se polifônico (o locutor representa o discurso de um terceiro ou comenta a fala de um terceiro). Com a verificação do tipo de discurso representado nesses comentários metadiscursivos, foi possível obter três tipos de comentários metadiscursivos:

1) Comentário metadiscursivo autofônico: o locutor avalia negativa ou positivamente seu próprio comportamento linguageiro ao longo do debate ou mesmo ao longo da campanha eleitoral.

2) Comentário metadiscursivo diafônico: o locutor avalia negativa ou positivamente o comportamento linguageiro do interlocutor (adversário ou integrante da plateia).

3) Comentário metadiscursivo polifônico: o locutor avalia negativa ou positivamente o comportamento linguageiro de terceiros (correligionários, assessores, o programa político etc).

A tabela 2 apresenta o número dos tipos de comentários metadiscursos presentes em cada debate e produzidos por candidato:

Tabela 2: Total de cada tipo de comentário metadiscursivo por debate e por candidato

\begin{tabular}{|l|c|c|c|c|c|c|c|}
\hline \multirow{2}{*}{ Candidatos } & \multicolumn{2}{|c|}{$\begin{array}{c}\text { Tipo 1 } \\
\text { (autofônico) }\end{array}$} & \multicolumn{2}{c|}{$\begin{array}{c}\text { Tipo 2 } \\
\text { (diafônico) }\end{array}$} & \multicolumn{2}{c|}{$\begin{array}{c}\text { Tipo 3 } \\
\text { (polifônico) }\end{array}$} & \multirow{2}{*}{$\begin{array}{c}\text { Total } \\
(\mathbf{1 0 0 \% )}\end{array}$} \\
\cline { 2 - 7 } & $\mathbf{N}$ & $\mathbf{\%}$ & $\mathbf{N}$ & $\mathbf{\%}$ & $\mathbf{N}$ & $\mathbf{\%}$ & \\
\hline José Serra & 0 & - & 9 & 47,4 & 10 & 52,6 & 19 \\
\hline $\begin{array}{l}\text { Fernando } \\
\text { Haddad }\end{array}$ & 3 & 9 & 24 & 72,8 & 6 & 18,2 & 33 \\
\hline Total parcial & $\mathbf{3}$ & $\mathbf{5 , 7}$ & $\mathbf{3 3}$ & $\mathbf{6 3 , 5}$ & $\mathbf{1 6}$ & $\mathbf{3 0 , 8}$ & $\mathbf{5 2}$ \\
\hline Dilma Rousseff & 2 & 6,4 & 25 & 80,7 & 4 & 12,9 & 31 \\
\hline Aécio Neves & 2 & 5,3 & 31 & 81,6 & 5 & 13,1 & 38 \\
\hline Total parcial & $\mathbf{4}$ & $\mathbf{5 , 8}$ & $\mathbf{5 6}$ & $\mathbf{8 1 , 1}$ & $\mathbf{9}$ & $\mathbf{1 3 , 1}$ & $\mathbf{6 9}$ \\
\hline Total geral & $\mathbf{7}$ & $\mathbf{5 , 7}$ & $\mathbf{8 9}$ & $\mathbf{7 3 , 6}$ & $\mathbf{2 5}$ & $\mathbf{2 0 , 7}$ & $\mathbf{1 2 1}$ \\
\hline
\end{tabular}

Fonte: Elaboração dos autores.

Como evidencia a tabela, o comentário metadiscursivo de tipo 1 (autofônico) foi o que teve menor número de ocorrências. O comentário de tipo 2 (diafônico) é predominante em ambos debates. Já o de tipo 3 (polifônico) ocorreu predominantemente no debate entre Fernando Haddad e José Serra. As razões para esses resultados serão discutidas no próximo item.

\subsection{Combinação das formas de organização relacional e enunciativa e do módulo referencial}

Nesta etapa final da pesquisa, os resultados da etapa anterior (combinação das formas de organização relacional e enunciativa) foram combinados com o estudo do módulo referencial, que descreveu propriedades típicas (representação conceitual) do gênero debate eleitoral, com a finalidade de compreender a função geral do comentário metadiscursivo, bem como as funções que cada tipo de comentário metadiscursivo (autofônico, diafônico, polifônico) exerce nesse gênero.

Quando à função geral do comentário metadiscursivo, vimos no item sobre o módulo referencial que o debate se caracteriza por colocar frente a frente adversários que disputam um cargo político. Essa propriedade do debate motiva que cada candidato, na busca por revelar ao eleitor que suas 
propostas são as únicas capazes de solucionar os problemas vivenciados pela população, empregue recursos linguísticos com a função de desqualificar ou desmerecer a visão de mundo e as propostas do oponente. Nesse contexto, o comentário metadiscursivo surge como um recurso especialmente adequado para exercer essa função, tendo em vista a possibilidade de ele ser empregado para, retomando a fala do adversário ou de terceiros, desqualificar essa fala. Não por acaso, o comentário diafônico, aquele que avalia a fala do interlocutor, foi o mais empregado em ambos os debates estudados (tabela 2).

Além dessa função geral, o comentário metadiscursivo pode ser um recurso particularmente útil ao candidato da oposição, que precisa desmerecer o passado político ou as realizações do candidato da situação. No debate, é comum o candidato da situação listar as realizações que fez ou vem fazendo durante o mandato, as quais funcionariam como uma garantia de que, se reeleito, saberá agir em prol da população. Usando o comentário metadiscursivo, o candidato da oposição costuma retomar as realizações mencionadas, a fim de revelar que não tiveram os impactos positivos mencionados, ou não foram conduzidas de maneira honesta e desinteressada. Não por acaso, em ambos os debates, os candidatos da oposição (Fernando Haddad e Aécio Neves) produziram mais comentários metadiscursivos do que os da situação (Dilma Rousseff e José Serra) (tabela 1). Os comentários permitem, portanto, aos candidatos da oposição revelarem ou ressaltarem os supostos problemas dos mandatos em curso dos adversários, apresentando-se como uma esperança de renovação política. Quanto à função que cada tipo de comentário metadiscursivo exerce, na sequência deste item, abordaremos separadamente cada um dos tipos, apontando suas funções com base em exemplos representativos de cada um deles.

\subsubsection{Comentário metadiscursivo autofônico}

Como exposto, esse tipo de comentário permite ao locutor avaliar negativa ou positivamente seu próprio comportamento linguageiro ao longo do debate ou mesmo ao longo da campanha eleitoral. Embora tenha sido o tipo de comentário com menor número de ocorrências no corpus (tabela 2), ele exerce uma função importante, porque permite ao locutor construir uma autoimagem (face) favorável para si, reivindicando valores sociais positivos (honestidade, sabedoria, competência, idoneidade), como ilustra este exemplo.

Aécio Neves: (...) (17) Eu governei Minas, com um orgulho enorme, candidata, por oito anos, (18) e levei Minas Gerais, (19) que não é o mais rico dos estados brasileiros, (20) é o segundo mais populoso, (21) a ter a melhor educação fundamental do Brasil. (22) E quem fez, candidata, tem mais autoridade para dizer que vai fazer.

No ato (22), o candidato comenta o próprio discurso (atos 17-21), ressaltando que teria mais autoridade do que a adversária para prometer melhorias na educação, pois teria alcançado resultados positivos em Minas Gerais, quando governador do estado. De qualquer forma, como informado, esse foi o tipo de comentário metadiscursivo que apresentou menor número de ocorrências, o que pode encontrar uma explicação no fato de que seu uso reiterado pode ter como efeito fazer com que o locutor seja visto como um candidato presunçoso, vaidoso ou arrogante. A explicação estaria, portanto, no tabu que, em sociedades como a nossa, envolve o autoelogio (KERBRAT-ORECCHIONI, 1992). 


\subsubsection{Comentário metadiscursivo diafônico}

Esse é o tipo de comentário com o qual o candidato avalia negativa ou positivamente o comportamento linguageiro do interlocutor (adversário ou integrante da plateia). O comentário diafônico foi o que apresentou maior número de ocorrências no corpus (tabela 2). A explicação para esse resultado está na natureza essencialmente polêmica do debate. Como ressaltamos no item sobre o módulo referencial, o dissenso acerca dos tópicos abordados é um traço característico do gênero. Essa característica do debate se reflete na linguagem empregada pelos adversários, que, utilizando uma gama variada de recursos linguísticos, tentam, sempre que a oportunidade surge, desqualificar o oponente, criticando suas ideias, valores e propostas, bem como o segmento (o partido) a que este pertence. Acrescentando-se ao conjunto dos recursos mencionados ao final do item sobre o módulo referencial, o comentário metadiscursivo diafônico permite ao locutor desqualificar o adversário, retomando e reinterpretando sua fala conforme os próprios interesses. Exemplo representativo desse tipo de comentário encontra-se neste trecho:

José Serra: (1) Olha, como eu disse, (2) o piso salarial foi elevado de 1200, para 2600. (3) Isso valoriza o professor, (...) (8) Mais ainda, nós vamos criar um centro de treinamento e reciclagem permanente dos professores do município. (9) Para reforçar a qualidade das aulas, a qualidade da docência. (...)

Fernando Haddad: (1) Serra, com o perdão da palavra, (2) a educação não é propriamente a tua área. (3) Professor não é reciclado nem treinado. (4) Essas palavras não se adequam ao educador. (5) O educador é formado, (6) tem sua formação inicial, continuada. (7) Reciclagem e treinamento você usa para outras coisas, (8) você não pode usar para professor. (9) Estou te orientando (10) para você não cometer esse deslize novamente. (...)

Nos atos (1-8), Haddad retoma a proposta de Serra (criação de um centro de treinamento e reciclagem de professores), para desqualificá-la e revelar a suposta visão do adversário sobre os professores, segundo a qual estes, assim como "outras coisas" (lixo), seriam recicláveis. Com esse exemplo, verifica-se como o comentário metadiscursivo pode ser um recurso importante para acentuar o caráter polêmico do debate. Além dessa função de atacar a imagem do adversário, o comentário diafônico pode ter como função a valorização da face do interlocutor. Mas, no debate, o interlocutor cujo comportamento se comenta positivamente é sempre o integrante da plateia convidado a fazer uma pergunta e nunca o adversário político. Esse uso do comentário diafônico ocorreu apenas no debate entre Dilma Rousseff e Aécio Neves, devido à sua composição, que contava com a possibilidade de integrantes da plateia presente no estúdio fazerem perguntas aos candidatos. O exemplo abaixo ilustra essa função:

Luiz Alexandre Filho: (...) (6) Qual será a sua política para quem mora de aluguel, (7) pois está cada vez mais difícil e muito mais caro alugar uma casa, (8) os preços estão muito acima da inflação? (9) Moro há 15 anos (10) e o meu aluguel triplicou nos últimos quatro anos.

Dilma Rousseff: (1) Luiz Alexandre, muito boa a pergunta. (2) Você vai me dar a oportunidade para mim falar do Minha Casa, Minha Vida.

No ato (1), a candidata avalia positivamente a fala do interlocutor (pergunta feita nos atos (6-8)), valorizando sua participação e, ao mesmo tempo, mostrando-se aos eleitores de modo geral como uma pessoa cortês. 


\subsubsection{Comentário metadiscursivo polifônico}

Com esse tipo de comentário, o locutor avalia negativa ou positivamente o comportamento linguageiro de terceiros (correligionários, assessores, o programa político etc.). Como exposto na tabela 2, esse tipo de comentário teve maior número de ocorrências no debate entre Fernando Haddad e José Serra. Esse resultado se explica pelo fato de que, nesse debate, os candidatos se valeram com maior frequência da estratégia de comentar propostas ou ideias do adversário, falando diretamente para uma das câmeras e simulando, dessa forma, um diálogo com o espectador. Usando essa estratégia, o locutor faz do eleitor seu interlocutor e, portanto, um participante do debate e, ao mesmo tempo, transforma o adversário em um terceiro. Por isso, os comentários metadiscursivos em que o candidato se refere ao adversário na $3^{\mathrm{a}}$ pessoa devem ser classificados como polifônicos e não como diafônicos. É o que ocorre neste trecho em que Haddad comenta as propostas do adversário sobre a saúde da mulher.

Fernando Haddad: (01) Na minha opinião, (02) o candidato José Serra tem uma visão muito restrita da mulher. (03) Ele vê a mulher apenas como gestante. (...)

No debate entre Dilma Rousseff e Aécio Neves, comentários polifônicos também ocorrem. Diferentemente do debate entre Haddad e Serra, esse contava com uma plateia presente no estúdio. Por isso, o debate entre Dilma Rousseff e Aécio Neves se caracterizou pela alternância de blocos em que os adversários dialogavam entre si, trocando perguntas e respostas, e blocos em que integrantes da plateia faziam perguntas aos candidatos. No exemplo a seguir, extraído do segundo bloco do debate, a candidata dialoga diretamente com a integrante da plateia que, no início desse bloco, havia perguntado aos adversários quais as propostas de ambos para acabar com a corrupção no país. Em todo este trecho, a candidata faz um comentário polifônico sobre a resposta que o adversário havia dado na intervenção anterior:

Dilma Rousseff: (1) Adriana, veja você que quem fala é o representante do partido que tinha uma prática, Adriana, que era engavetar todas as investigações. (2) Tudo que era investigação engavetava. (3) De deputado, de senador, de ministro. (4) Isso, Adriana, levou o Brasil a sempre ter um conjunto de julgamentos que ninguém nunca viu e nem deu fé. (5) Foram todos soltos. (...)

Os exemplos apresentados revelam que, assim como os comentários diafônicos, os polifônicos que avaliam o comportamento do adversário podem ser usados como recursos importantes para desqualificar o outro, na tentativa de minar a autoimagem que este tenta construir ao longo do debate. Mas os comentários polifônicos apresentam uma vantagem em relação aos diafônicos. Com os primeiros, o locutor pode criar o efeito de que o adversário não participa da interação (ou mesmo do jogo político), sendo relegado ao estatuto de $3^{\text {a }}$ pessoa ou de "não pessoa" (BENVENISTE, 1976), e, consequentemente, de que suas ideias são absurdas, inapropriadas ou desprovidas de interesse. Nesse sentido, os comentários polifônicos podem ser até mais agressivos e polêmicos do que os diafônicos. Mas, além de permitir o ataque ao adversário, o comentário metadiscursivo polifônico permite também o ataque a outras instâncias enunciativas. É o que revela este exemplo:

Aécio Neves: (...) (6) A revista [Veja] hoje publica que o delator, (7) um dos delatores do "petrolão", (8) disse que a senhora e o ex-presidente Lula tinham conhecimento da corrupção na Petrobras, (9) uma oportunidade da senhora responder aos brasileiros. (10) A senhora sabia, candidata, da corrupção na Petrobras? 
Dilma Rousseff: (1) Candidato, é fato que o senhor tem feito uma campanha extremamente agressiva a mim. (2) Isso é reconhecido por todos os eleitores. (3) Agora essa revista que fez e que faz sistematicamente oposição a mim, faz uma calúnia e uma difamação do porte que ela fez hoje. (4) E o senhor endossa.

No trecho, a candidata busca, por meio do comentário sublinhado (ato (3)), desacreditar as informações expressas por uma revista e, portanto, a acusação do adversário, que se baseia nessas informações.

\section{Considerações finais}

Com a pesquisa apresentada neste trabalho, o objetivo foi obter uma definição do comentário metadiscursivo que evidencie a complexidade do conceito. Estudando os comentários presentes em dois debates eleitorais, a pesquisa se valeu de contribuições teóricas e metodológicas do Modelo de Análise Modular do Discurso e seguiu três etapas principais. Inicialmente, descrevemos o gênero debate eleitoral do ponto de vista do módulo referencial, reunindo, em uma representação do conceito "debate eleitoral", propriedades que tipicamente podem ser atribuídas a esse gênero. Em seguida, estudamos a forma de organização relacional dos debates, a fim de identificar todas as ocorrências de relações de comentário neles presentes. Por fim, estudamos os comentários identificados na etapa anterior do ponto de vista da forma de organização polifônica.

$\mathrm{O}$ estudo dessa última etapa se fez em duas subetapas. Na primeira, que combinou os estudos das formas de organização relacional e enunciativa, identificamos os comentários metadiscursivos, extraindo do conjunto dos comentários identificados na etapa anterior aqueles que trazem segmentos de discursos representados e que, por isso, são metadiscursivos. Feita a identificação dos comentários metadiscursivos, obtivemos três tipos de comentário: autofônico (o locutor comenta seu próprio discurso), diafônico (o locutor comenta o discurso do interlocutor) e polifônico (o locutor comenta o discurso de terceiros). Na segunda subetapa da forma de organização polifônica, estudamos as funções que o comentário metadiscursivo exerce nos debates estudados, combinando resultados da subetapa anterior com o estudo do módulo referencial sobre propriedades típicas do gênero. Constatamos que o comentário autofônico permite ao locutor construir uma autoimagem (face) favorável para si. Já o diafônico pode ser empregado tanto para desacreditar o interlocutor quanto para enaltecê-lo. No caso do debate, o locutor usa esse tipo de comentário para desacreditar o adversário político e enaltecer o integrante da plateia. Por fim, o polifônico permite ao locutor desqualificar um terceiro que, no debate, pode ser tanto uma instância ausente do estúdio de realização do debate, quanto o adversário a quem o locutor se refere na $3^{\mathrm{a}}$ pessoa.

Neste trabalho, articulamos de forma progressiva, a partir da combinação dos resultados de cada etapa e subetapa, noções mais elementares, próprias de diferentes módulos e formas de organização, tais como gênero debate, estrutura hierárquica, relação de comentário, discurso representado, quadro interacional, tipos de discurso (autofônico, diafônico, polifônico). Essa articulação de noções nos permitiu construir progressivamente uma noção de comentário metadiscursivo que permite evidenciar a natureza complexa do fenômeno. Ao final do percurso de análise, é possível definir o comentário metadiscursivo como sendo uma relação de discurso por meio da qual o locutor emprega um segmento de discurso representado para comentar, avaliando, uma informação da memória discursiva cuja origem é o comportamento linguageiro do próprio locutor (comentário metadiscursivo autofônico), do interlocutor (comentário metadiscursivo diafônico) ou de terceiro (comentário metadiscursivo polifônico). 
Com base na definição e nas funções do comentário metadiscursivo propostas neste trabalho, podemos vislumbrar alguns direcionamentos para pesquisas futuras. Um deles seria investigar, de maneira mais sistemática, o papel de cada subtipo de comentário metadiscursivo no trabalho de face, ou seja, na negociação de faces e territórios (GOFFMAN, 2011[1967], BROWN; LEVINSON, 1987, ROULET, 1999) ${ }^{10}$. Outro desdobramento instigante seria verificar se, em outras situações de ação (fóruns de discussão, redes sociais, aulas, entrevistas, reuniões de trabalho etc), o comentário metadiscursivo exerce as mesmas funções gerais e específicas que exerce em debates eleitorais.

10 Essa perspectiva de análise foi explorada por Cunha (2017a), em estudo sobre as ocorrências do conector mas nos dois debates eleitorais estudados neste trabalho. 


\section{Referências}

AQUINO, Z. G. O. Diálogos da mídia - o debate televisivo. In: PRETI, D. (Org.) Diálogos na fala e na escrita. São Paulo: Humanitas, 2008, p. 171-194.

AMOSSY, R. Apologia da polêmica. São Paulo: Contexto, 2017.

BENVENISTE, E. Problemas de linguística geral. São Paulo: Ed. Nacional, Ed. Universidade de São Paulo, 1976.

BROWN, P; LEVINSON, S. Politeness: some universals in language use. Cambridge: Cambridge University Press, 1987.

BURGER, M. La gestion des activités:pratiques sociales, roles interactionnels et actes de discours. Cahiers de linguistique française. Genebra, 2004. v. 26, p. 177-196.

CUNHA, G. X. Para entender o funcionamento do discurso: uma abordagem modular da complexidade discursiva. Curitiba: Appris, 2014.

CUNHA, G. X. As relações retóricas e a negociação de faces em debate eleitoral. Confluência, Rio de Janeiro, n. 47, p. 205-238. 2014a.

CUNHA, G. X. O papel das relações retóricas na negociação de faces em debate eleitoral. 2015. 170f. Relatório de pesquisa (Pós-Doutorado em Linguística) - Faculdade de Letras, Universidade Federal de Minas Gerais, Belo Horizonte.

CUNHA, G. X. Conectores e processo de negociação: uma proposta discursiva para o estudo dos conectores. Fórum Linguístico, Santa Catarina, v. 14, p. 1699-1716, 2017.

CUNHA, G. X. O papel dos conectores na co-construção de imagens identitárias: o uso do mas em debates eleitorais. ALFA, Araraquara, v. 61, p. 599-623, 2017 a.

CUNHA, G. X.; BRAGA, P. B. O comentário metadiscursivo como estratégia argumentativa em debates eleitorais. EID\&A, Ilhéus, n. 12, p. 101-118, 2016.

CUNHA, G. X.; MARINHO, J. H. C. A expressão conectiva na verdade: contribuições para uma abordagem polifônica dos conectores reformulativos. Signo, Santa Cruz do Sul, v. 42, p. 53-64, 2017.

FILlietTAZ, L. Actions, activités et discours. Tese (Doutorado em Linguística) - Faculdade de Letras, Universidade de Genebra, Genebra, 2000.

FILLIETTAZ, L.; ROULET, E. The Geneva Model of discourse analysis: an interactionist and modular approach to discourse organization. Discourse Studies, v. 4, n. 3, 2002, p. 369-392.

GOFFMAN, E. Ritual de interação: ensaios sobre o comportamento face a face. Petrópolis: Vozes, 2011[1967].

HYLAND, K. Metadiscourse: what is it and where is it going? Journal of Pragmatics, 113, 2017, p. 16-29.

JUBRAN, C. C.A. S. Especificidades da referenciação metadiscursiva. In: KOCH, I. G. V.; MORATO, E. M.; BENTES, A. C. (orgs.) Referenciação e discurso. São Paulo: Contexto, 2005, p. 219-241.

KERBRAT-ORECCHIONI, C. Les interactions verbales. Paris: Colin, 1992.

KOTSCHI, Thomas. Procédés d'évaluation et de commentaire métadiscursifs comme stratégies interactives. Cahiers de Linguistique Française, Genebra, 1986. n. 7, p. 207-230

MARINHO, J. H. C. Uma abordagem modular e interacionista da organização do discurso. Revista da Anpoll, São Paulo, 2004. n. 16, p. 75-100.

MARTEL, G. Performance... et contre-performance communicationnelles: des stratégies argumentatives pour le débat politique télévisé. Argumentation et Analyse du Discours. Tel-Aviv, v. 1, 2008, p. 02-12. 
ROULET, E. La description de l'organisation du discours. Paris: Didier, 1999.

ROULET, E. Une approche modulaire de la problematique des relations de discours. In: MARI, H. et al. (orgs.) Análise do discurso em perspectivas. Belo Horizonte: FALE/UFMG, 2003, p. 149-178.

ROULET, E. Les relations de discours rhétoriques et praxéologiques dans la description des propriétés des constituants parenthétiques. Travaux de linguistique. n. 49, 2004, p. 09-17.

ROULET, E.; FILLIETTAZ, L.; GROBET, A. Un modèle et un instrument d'analyse de l'organisation du discours. Berne: Lang, 2001.

SERAFIM, M. S. Os comentários metadiscursivos em narrativas produzidas por crianças: a materialização do sujeito-autor. Veredas, Uberlândia, v. 14, 2010, p. 142-156.

SILVA, L. A. Descortesia e (des)construção da imagem pública. In: PRETI, D.; LEITE, M. Q. (Org.) Comunicação na fala e na escrita. São Paulo: Humanitas, 2013, p. 93-120.

SANDRÉ, M. Débat politique télévisé et stratégies discursives: la visée polémique des ratés du système des tours. In: BURGER, M.; JACQUIN, J.; MICHELI, R. (Org.) Actes du colloque «Le français palé dans les médias: les médias et le politique». 2009, p. 01-13.

SULLET-NYLANDER, F. ; ROITMAN, M. De la confrontation politico-journalistique dans les grands duels politiques télévisés: questions et préconstruits. In : BURGER, M.; JACQUIN, J.; MICHELI, R. (Org.) Actes du colloque «Le français palé dans les médias: les médias et le politique», 2009, p. 01-19. 